\title{
PERBANDINGAN PENGGUNAAN FILTER UDARA STANDAR DAN RACING TERHADAP PERFORMA DAN EMISI GAS BUANG MESIN SEPEDA MOTOR EMPAT LANGKAH
}

\author{
Agus Fatkhuniam $^{1}$, M. Burhan Rubai Wijaya ${ }^{2}$, Angga Septiyanto ${ }^{3}$ \\ Pendidikan Teknik Otomotif, Universitas Negeri Semarang \\ Email: agusfathkuniam@gmail.com
}

\begin{abstract}
This research aims to determine the performance increase of using racing air filters compared to standard air filters on a four-stroke vehicle. Performance being tested are power, torque and exhaust emissions. This is an experimental research conducted on a Honda Supra X 125 PGM-FI motorcycle. Data were analyzed using descriptive statistics and the collection is presented in the form of tables, graphs, and calculated averages. Results show that racing air filter 1 have a power of $7.35 \mathrm{HP}$ (2.3\% increase) and racing air filter 2 have a power of 7,3 HP (1.6\% increase). The torque tests shows that Racing filter 1 has a torque of 10,588 Nm and the racing air filter 2 has a torque of 10,585 Nm, while standard filter has only $10.42 \mathrm{Nm}$. CO gas emissions resulting from the use of racing air filters 1 increased by 28\% from standard air filters and for racing air filter 2 CO 2 emissions decreased by 6\%. At the exhaust emissions of HC, racing air filters 1 emissions increased by $16 \%$ and racing air filter 2 decreased by $9 \%$.
\end{abstract}

Keywords: engine performance, exhaust emissions, four stroke motorcycle

\begin{abstract}
ABSTRAK
Penelitian ini bertujan untuk membuktikan adanya perbedaan filter udara racing dengan filter udara standar terhadap performa kendaraan empat langkah, berupa daya, torsi dan emisi gas buang. Penelitian dilakukan secara eksperimen pada sepeda motor Supra X 125 PGM-FI. Analisis data menggunakan statistik deskriptif dengan penyajian data berupa tabel, grafik. Hasil penelitian menunjukkan bhawa perhitungan rata-rata. sebesar 7,35 Hp dengan meningkat 2,3\% dan filter udara racing 2 meningkat sebesar 1,6 \% menjadi 7,3 HP dibandingkan dari hasil filter udara standar sebesar 7,18 Hp, torsi filter udara racing 1 meningkat sebesar 1,6\% menjadi 10,588 N.m dan filter udara racing 2 meningkat 1,5\% menjadi 10,585 N.m dibandingkan hasil dari penggunaan filter standar sebesar 10,42 N.m. Emisi gas buang CO yang dihasilkan dari penggunaan filter udara racing 1 meningkatan 28\% dari filter udara standar 0,803\% menjadi 1,034\% dan CO filter udara racing 2 ada penurunan $6 \%$ menjadi $0,754 \%$ dari CO filter udara standar $0,803 \%$, dengan selisih perbedaan $0,231 \%$ dan 0,049\% dari penggunaan filter udara standar. Pada emisi gas buang HC filter udara racing 1 terdapat peningkatan sebesar 16\% menjadi $142 \mathrm{ppm}$ dari hasil filter standar dan penurunan $9 \%$ dari penggunaan filter udara racing 2 sebesar 111 ppm dibandingkan HC yang dihasilkan filter standar sebesar 122 ppm, dengan selisih 20 ppm dan 11 ppm dari HC yang dihasilkan filter udara standar.
\end{abstract}

Kata kunci: performa mesin, emisi gas buang, motor empat langkah

\section{PENDAHULUAN}

Perkembangan di sektor transportasi di Indonesia khususnya sepeda motor yang semakin hari semakin bertambah, membawa dampak terjadinya peningkatan polusi udara serta peningkatan konsumsi bahan bakar. Kebutuhan akan bahan bakar minyak (BBM) dari tahun ke tahun yang terus meningkat, mengakibatkan semakin menipisnya cadangan minyak bumi. Kebutuhan masyarakat terhadap kendaraan pribadi khususnya sepeda motor merupakan salah satu produk otomotif yang lebih banyak dipilih daripada kendaraan roda empat, hal ini dapat dilihat dari data Badan Pusat Statistik. Pada tahun 2012 jumlahnya lebih dari 76 juta unit, tahun 2013 meningkat 10\% menjadi 84 juta dan ditahun 2014 jumlah kendaraan bermotor jenis roda dua ini meningkat 9\% menjadi 92 juta lebih pengguna 
sepeda motor yang ada di indonesia (Suryamin, 2014).

Tabel 1. Perkembangan Jumlah Kendaraan Bermotor Menurut Jenis, 2012-2014

\begin{tabular}{lccc}
\hline Jenis & \multicolumn{3}{c}{ Jumlah Kendaraan Bermotor (Unit) } \\
\cline { 2 - 4 } $\begin{array}{l}\text { Kendaraan } \\
\text { Bermotor }\end{array}$ & 2012 & 2013 & 2014 \\
\hline $\begin{array}{l}\text { Mobil } \\
\text { Penumpang }\end{array}$ & 10.432 .259 & 11.484 .514 & 12.599 .138 \\
Mobil Bus & 2.273 .821 & 2.286 .309 & 2.398 .846 \\
$\begin{array}{l}\text { Mobil } \\
\text { Barang }\end{array}$ & 5.286 .061 & 5.615 .494 & 6.235 .136 \\
$\begin{array}{l}\text { Sepeda } \\
\text { Motor }\end{array}$ & 76.381 .183 & 84.732 .652 & 92.976 .240 \\
\hline Jumlah & 94.373 .324 & 104.118 .969 & 114.209 .360 \\
\hline
\end{tabular}

Sepeda motor sebagai alat transportasi menggunakan motor bakar sebagai pembangkit tenaga untuk menggerakkan roda, motor bakar merupakan mesin dengan pembakaran dalam (Internal Combustion Engine). Salah satu motor bakar torak yang banyak digunakan adalah jenis motor bensin (otto), motor bakar mempunyai peranan yang sangat penting dalam kehidupan manusia sehari-hari, terutama di bidang transportasi. Motor pembakaran dalam (Internal Combustion Engine) yang banyak digunakan adalah jenis 4 langkah, dengan empat kali putaran mesin yang terdiri dari langkah hisap, langkah kompresi, langkah kerja, dan langkah buang. Dalam pembakaran memerlukan tiga syarat utama, yaitu bahan bakar, oksigen, dan pengapian. Kendaraan roda dua saat ini telah banyak inovasi, salah satunya yaitu inovasi dalam peningkatan engine performance (performa mesin), hal tersebut selalu menjadi bahan penelitian hingga mendapat hasil yang sempurna.

Banyak cara untuk meningkatkan performa kendaraan yang ramah lingkungan, salah satunya di bagian pengapian mesin. Bagian pengapian untuk menaikkan performa dengan mengganti CDI (Capacitor Discharger Ignition), magnet, coil. Pada bagian mesin bisa dengan menaikkan kapasitas mesin atau membesarkan diameter piston (bore up) dan mengganti karburator dengan ukuran yang lebih besar. Dalam meningkatkan performa juga bisa didapat dengan cara menggunakan filter racing.
Beberapa jenis karburator dilengkapi dengan filter untuk menyaring udara yang masuk ke karburator, sistem kerja kaburator salah satunya dipengaruhi oleh filter, sehingga kinerja engine akan dipengaruhi. Efisiensi pemasukan udara dan bahan bakar juga sangat berpengaruh terhadap proses pembakaran. Dalam proses pembakaran memerlukan udara yang bersih untuk campuran bahan bakar menjadi homogen agar proses pembakaran di dalam silinder lebih sempurna.

Filter juga memiliki fungsi untuk meredam suara kebisingan yang dihasilkan dari udara yang masuk ke karburator. Apabila tanpa meggunakan filter, udara yang masuk ke karburator atau injeksi akan berlebihan dan juga udara yang masuk banyak debu. Partikel debu yang ikut masuk ke dalam karburator dapat menumpuk di dalam karburator sehingga menyumbat aliran bahan bakar di karburator, maka bahan bakar yang akan disuplai akan terhambat dan jumlahnya akan sedikit sehingga membuat campuran udara dan bahan bakar menjadi tidak seimbang.

Campuran udara dan bahan bakar yang tidak seimbang dan homogen akan mengakibatkan pembakaran tidak sempurna dan menurunnya kinerja mesin. Pembakaran yang tidak sempurna akan menghasilkan gas hasil pembakaran yang tidak sempurna juga, seperti gas CO dan HC. Apabila pencampuran bahan bakar dan udara berlangsung dengan baik, maka pembakaran bahan bakar akan menjadi sempurna dan efisiensi dari kinerja mesin tersebut akan meningkat.

Cara untuk meminimalisir kadar emisi gas buang dengan menyempurnakan proses pembakaran, untuk mendapatkan pembakaran yang sempurna maka diperlukan suatu campuran bahan bakar dengan udara yang homogen. Campuran udara dan bahan bakar yang homogen dapat dilakukan dengan membuat aliran udara menjadi turbulen. Dari setiap proses pembakaran selalu dihasilkan gas buang (emisi gas buang) yang dapat mencemari lingkungan diantaranya adalah Hidrokarbon (HC), Karbon monoksida (CO). 
Gas yang dibutuhkan dalam pembakaran adalah oksigen untuk membakar bahan bakar yang mengandung molekul karbon dan hidrogen. (Pratama dan Wardono, 2014: 28) "Di alam bebas jumlah molekul gas nitrogen memiliki jumlah terbesar (78\%) dibandingkan jumlah oksigen (21\%), sedangkan 1\% lainnya adalah uap air dan kandungan gas lainnya. Hal ini jelas mengganggu proses pembakaran karena nitrogen dan uap air akan mengambil panas di ruang bakar, yang menyebabkan pembakaran tidak sempurna.” Agar mendapatkan pembakaran sempurna maka diperlukan filter yang dapat menyaring debu atau kotoran-kotoran dan berfungsi sebagai penyaring gas-gas yang tidak diperlukan dalam proses pembakaran.

Filter racing diharapkan udara yang masuk ke karburator lebih bersih dan dengan aliran udara yang turbulen (pusaran udara) dapat meningkatkan campuran bahan bakar dengan udara menjadi lebih homogen dan proses pembakaran menjadi sempurna. Sehingga performa yang didapat lebih baik dari sebelumnya dan emisi gas buang yang dihasilkan menjadi ramah lingkungan. Berdasarkan uraian latar belakang ini maka perlu dilakukan penelitian tentang "perbandingan filter standar dengan racing terhadap performa dan emisi motor empat langkah pada sepeda motor." Penelitian ini bertujuan untuk membuktikan adanya perbedaan performa mesin dan emisi gas buang menggunakan filter racing pada kendaraan empat langkah.

\section{METODE}

Bahan-bahan yang digunakan ada penelitian yaitu sepeda motor Honda Supra X 125 PGM-FI tahun 2010, filter udara standar dan filter udara racing, Alat yang digunakan untuk mengukur daya, tosi, dan emisi gas buang yaitu dynamometer dan gas analyzer. Skema penelitian ditunjukkan pada Gambar 1.

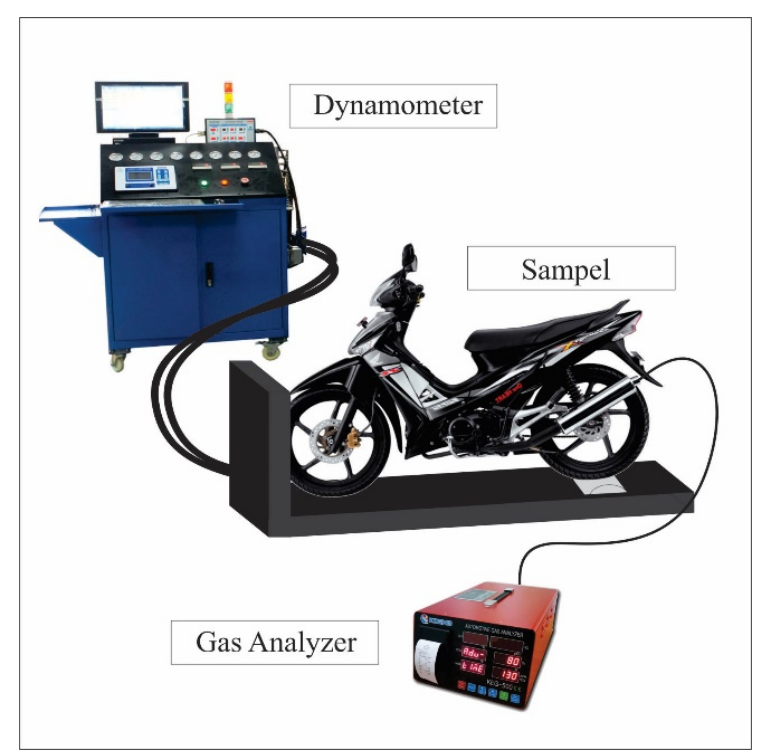

Gambar 1. Skema Penelitian

Sebelum melakukan penelitian mempersiapkan sepeda motor, melakukan pekerjaan tune up agar kondisi mesin pada saat pengetesan mendapatkan hasil data yang baik, lalu mesin sepeda motor yang akan diuji dinaikkan di atas mesin dynamometer dengan posisi roda belakang bertumpu pada sebuah roller dynamometer dan masukan gigi percepatan untuk uji daya dan torsi. Data informasi perubahan daya dan torsi pada setiap putaran mesin akan ditampilkan pada sebuah layar monitor komputer, sedangkan emisi gas buang dilihat dari alat uji emisi kendaraan bermotor (Gas Analyzer) untuk mengetahui indikasi efisiensi gas buang dari hasil pembakaran.

Data yang diperoleh dari hasil pengujian kemudian dihitung rata-rata, dimasukkan ke dalam tabel dan disajikan dalam bentuk grafik kemudian dideskripsikan menjadi kalimat agar mudah dipahami dan ditarik kesimpulannya, sehingga dapat diketahui perbandingan torsi, daya dan emisi gas buang yang dihasilkan (Sugiyono, 2014:147).

\section{HASIL DAN PEMBAHASAN}

Hasil dari penelitian yang sudah diuji daya mesin sepeda motor Supra X 125 PGM-FI 
diambil dari eksperimen menggunakan filter udara standar, filter udara racing 1 , dan filter udara racing 2 yang diambil datanya dengan menggunakan alat dynosport v3. Data yang didapat dari pengujian filter udara ditampilkan dalam bentuk tabel dan grafik sesuai dengan hasil uji daya.

Tabel 2. Hasil pengujian daya sepeda motor supra X 125 PGM-FI menggunakan filter udara standar dan filter udara racing

Daya (Hp) yang dihasilkan pada setiap

\begin{tabular}{cccc}
\hline \multirow{2}{*}{ Rpm } & \multicolumn{3}{c}{$\begin{array}{c}\text { Daya (Hp) yang dihasilkan pada setiap } \\
\text { filter udara }\end{array}$} \\
\cline { 2 - 4 } & $\begin{array}{c}\text { Filter } \\
\text { standar }\end{array}$ & $\begin{array}{c}\text { Filter } \\
\text { racing 1 }\end{array}$ & $\begin{array}{c}\text { Filter } \\
\text { racing 2 }\end{array}$ \\
\hline 2500 & 4 & 3,9 & 3,9 \\
3500 & 5,1 & 5,1 & 5,2 \\
4500 & 6,6 & 6,6 & 6,7 \\
5500 & 8,4 & 8,6 & 8,5 \\
6500 & 9,4 & 9,8 & 9,6 \\
7500 & 9,6 & 10,1 & 9,9 \\
\hline Rata-rata & 7,18 & 7,35 & 7,3 \\
\hline
\end{tabular}

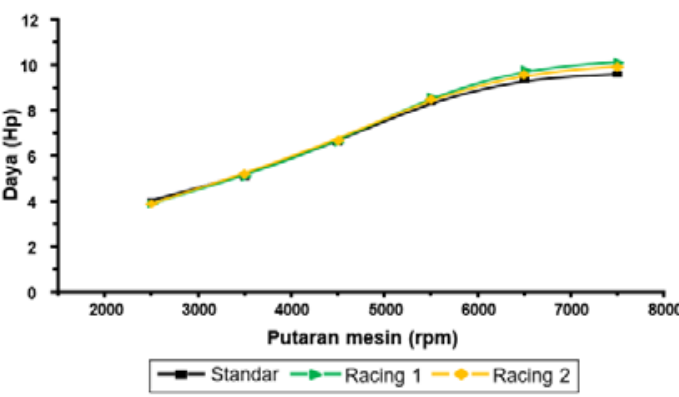

Gambar 2. Grafik pengujian daya

Berdasarka Gambar 2, daya yang dihasilkan dari penggunaan filter udara racing mengalami peningkatan dibandingkan dengan menggunakan filter udara standar. Putaran 7500 rpm daya tertinggi pada filter udara racing 1 dengan peningkatan sebesar 5\% dari daya yang dihasilkan oleh filter udara standar, dan 1\% dari filter udara racing 2. Selisih perbedaan antara filter udara racing 1 dengan filter udara standar 0,5 Hp, filter udara racing 2 dengan filter udara standar sebesar 0,3 Hp, dan 0,2 Hp pada filter udara racing 1 dengan filter udara racing 2 .
Hasil penelitian yang ditampilkan pada tabel dan grafik menunjukkan terdapat perbedaan rata-rata torsi yang dihasilkan pada setiap penggunaan filter udara standar dan filter udara racing dan perbedaanya adalah besaran torsi yang dihasilkan dari masing-masing penggunaan filter udara, dapat dilihat pada Gambar 3 sesuai dengan hasil uji torsi.

Tabel 3. Hasil pengujian torsi sepeda motor supa X125 PGM-FI dari menggunakan filter udara standar dan filter udara racing Torsi (N.m) yang dihasilkan pada setiap filter udara

\begin{tabular}{cccc} 
Rpm & filter udara & & \\
\cline { 2 - 4 } & $\begin{array}{c}\text { Filter } \\
\text { standar }\end{array}$ & $\begin{array}{c}\text { Filter racing } \\
1\end{array}$ & $\begin{array}{c}\text { Filter racing } \\
2\end{array}$ \\
\hline 2500 & 11,34 & 11,41 & 11,42 \\
\hline 3500 & 10,48 & 10,45 & 10,52 \\
\hline 4500 & 10,49 & 10,51 & 10,66 \\
\hline 5500 & 10,80 & 11,04 & 11,04 \\
\hline 6500 & 10,28 & 10,65 & 10,53 \\
\hline 7500 & 9,13 & 9,47 & 9,34 \\
\hline $\begin{array}{c}\text { Rata- } \\
\text { rata }\end{array}$ & 10,42 & 10,588 & 10,585 \\
\hline
\end{tabular}

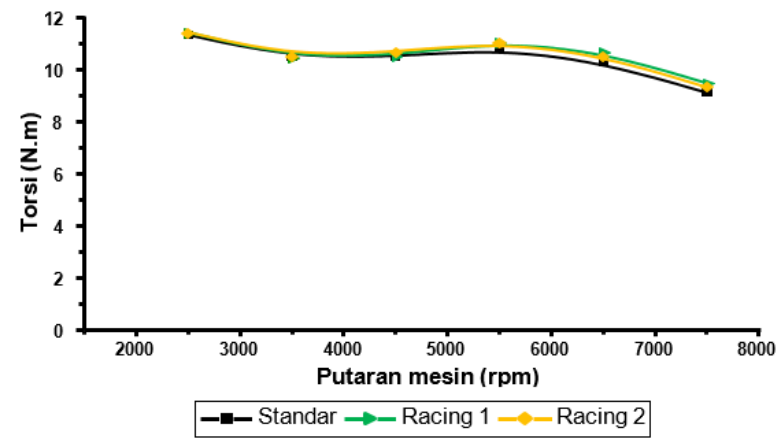

Gambar 3. Grafik pengujian torsi

Berdasarkan Gambar 3, torsi maksimal pada putaran $5500 \mathrm{rpm}$ torsi yang dihasilkan filter udara standar adalah 10,80 N.m dan pada filter udara racing 1 dan filter udara racing 2 torsi yang dihasilkan sama besarnya yaitu 11,04 N.m. Pada rpm ini filter udara racing 1 dan 2 mengalami peningkatan torsi sebesar 5\% dan 3\% dari rpm sebelumnya 10,51 N.m dan 10,66 N.m menjadi 11,04 N.m, sedangkan filter udara standar meningkat $2 \%$ menjadi 10,80 N.m dan torsi tertinggi pada filter udara racing sebesar 11,04 N.m dengan peningkatan 2\% dari torsi 
yang dihasilkan filter udara standar. Selisih antara filter udara standar dengan filter udara racing sebesar 0,24 N.m.

Pengujian emisi gas buang data yang dihasilkan dari mesin sepeda motor menggunakan filter udara standar, filter udara racing 1, dan filter udara racing 2 ditampilkan pada tabel dan grafik menunjukkan adanya perbedaan rata-rata dari tiap bahan yang digunakan, dapat di lihat pada Gambar 4 sesuai dengan hasil uji emisi CO.

Tabel 4. Kandungan CO yang dihasilkan sepeda motor supra X125 PGM-FI akibat penggunaan filter udara standar dan filter udara racing

\begin{tabular}{cccc}
\hline \multirow{2}{*}{$\begin{array}{c}\text { Putaran } \\
\text { rpm }\end{array}$} & $\begin{array}{c}\text { Filter } \\
\text { Standar }\end{array}$ & $\begin{array}{c}\text { Filter } \\
\text { Racing 1 }\end{array}$ & $\begin{array}{c}\text { Filter } \\
\text { Racing 2 }\end{array}$ \\
\cline { 2 - 4 } & CO (\%) & CO (\%) & CO (\%) \\
\hline 2500 & 0,684 & 0,843 & 1,048 \\
\hline 3500 & 0,783 & 0,709 & 0,767 \\
\hline 4500 & 0,943 & 0,71 & 1,288 \\
\hline Rata-rata & 0,803 & 0,754 & 1,034 \\
\hline
\end{tabular}

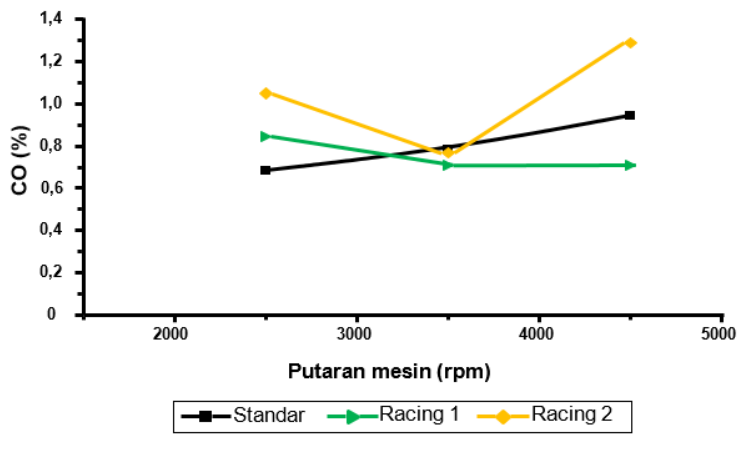

Gambar 4. Grafik pengujian emisi gas buang CO

Kadar CO emisi gas buang yang dihasilkan mesin dengan menggunakan filter udara standar, filter udara racing 1 , filter udara racing 2 sebesar 0,803\%, 0,754\%, dan 1,034\%. Selisih perbedaan filter udara standar dengan filter udara racing 1 sebesar 0,049\%, filter udara standar dengan filter udara racing 2 dengan selisih 0,231\%, CO tertinggi yang dihasilkan pada putaran $4500 \mathrm{rpm}$ terjadi peningkatan sebesar $20 \%$, 0,1\%, dan $67 \%$ dari rpm sebelumnya, CO tertinggi pada filter udara racing 2 sebesar 1,288\% dengan peningkatan 81\% dari CO yang dihasilkan filter udara racing 1 dan 36\% dari filter udara standar, selisih perbedaan $0,233 \%$ pada filter udara standar dengan filter udara racing 1, filter udara racing 2 dengan filter udara standar 0,345\%, dan $0,578 \%$ filter udara racing 1 dengan filter udara racing 2.

HC yang dihasilkan dari pengujian emisi gas buang yang menggunakan filter udara standar, filter udara racing 1 , dan filter udara racing 2 ditampilkan dalam bentuk tabel dan grafik dengan hasil rata-rata, dapat di lihat pada Gambar 5 sesuai hasil uji emisi HC.

Tabel 5. Kandungan HC sepeda motor supra X125 PGM-FI akibat dari penggunaan filter udara standar dengan filter udara racing

\begin{tabular}{cccc}
\hline \multirow{2}{*}{$\begin{array}{c}\text { Putaran } \\
\text { rpm }\end{array}$} & $\begin{array}{c}\text { Filter } \\
\text { Standar }\end{array}$ & $\begin{array}{c}\text { Filter } \\
\text { Racing 1 }\end{array}$ & $\begin{array}{c}\text { Filter } \\
\text { Racing 2 }\end{array}$ \\
\cline { 2 - 4 } & CO (\%) & CO (\%) & CO (\%) \\
\hline 2500 & 122 & 92 & 91 \\
\hline 3500 & 122 & 203 & 123 \\
\hline 4500 & 124 & 132 & 119 \\
\hline Rata-rata & 122 & 142 & 111 \\
\hline
\end{tabular}

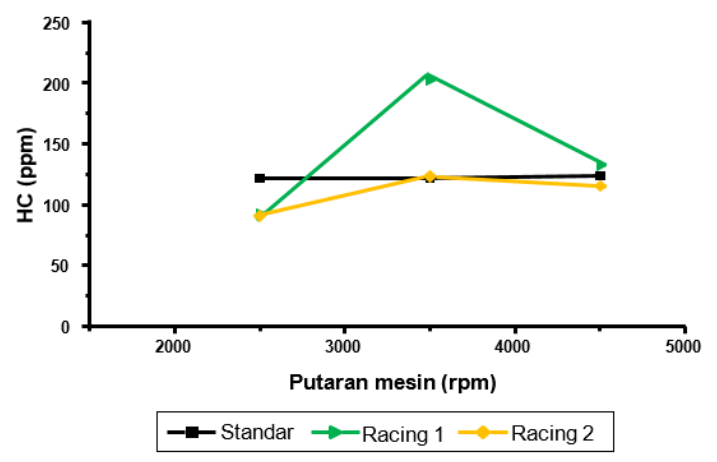

Gambar 5. Grafik pengujian emisi gas buang HC

Putaran 2500 rpm HC yang dihasilkan dari penggunaan filter udara standar 122 ppm, filter udara racing 1 sebesar 92 ppm, dan 91 ppm filter udara racing 2, putaran 3500 rpm HC yang dihasilkan dari pengujian filter udara standar, filter udara racing 1 , dan filter udara racing 2 meningkatan sebesar 80\% filter udara racing 1, dan 35\% filter udara racing 2 dari rpm sebelumnya. 
HC tertinggi dihasilkan dari filter udara racing 1 sebesar 203 ppm dan terjadi peningkatan $66 \%$ dari HC yang dihasilkan filter udara standar, 39\% dari filter udara racing 2.Putaran 4500 rpm gas emisi HC yang dihasilkan dari tiap-tiap filter udara terjadi penurunan pada filter udara racing 1 dan filter udara racing 2 sebesar 33\%, dan 3\%, pada filter udara standar terdapat peningkatan sebesar $1,6 \%$ dari rpm sebelumnya.

Hasil pengujian daya dan torsi yang terlihat digrafik menunjukkan adanya penurunan dan peningkatan dengan menggunakan filter udara standar dan filter udara racing, dilihat dari Grafik 2. Daya yang dihasilkan dari tiap-tiap rpm cenderung lebih stabil peningkatanya, daya terbesar yang dihasilkan terdapat pada penggunaan filter udara racing 1 sebesar 7,35 Hp, torsi terbesar dihasilkan pada penggunaan filter udara racing 1 dengan torsi 10,588 N.m, daya dan torsi yang dihasilkan dari filter udara racing 1 lebih tinggi daripada penggunaan filter udara standar dan filter udara racing 2.

Peningkatan daya dan torsi terjadi pada penggunaan filter udara racing 1 pada putaran 5500 - 7500 rpm dengan peningkatan daya sebesar $11 \%$ dari daya yang dihasilkan filter udara standar, daya tertinggi terdapat pada putaran 7500 rpm dan daya yang dihasilkan 10,1 Hp. Sedangkan peningkatan torsi terjadi pada putaran 3500 - 5500 rpm sebesar 10\% dan torsi yang dihasilkan lebih besar dari filter udara standar, filter udara racing 2 torsi tertinggi yang dihasilkan sama dengan filter udara racing 1 yaitu 11,04 N.m pada 5500 rpm dengan peningkatan 2,5\% dan 4,1\% dari filter udara standar pada putaran 3500-5500 rpm.

Pengujian daya dan torsi yang dihasilkan dari tiap-tiap penggunaan filter udara dengan hasil terbesar pada penggunaan filter udara racing 1 , hal ini terjadi karena fan (kipas) yang terdapat pada bagian depan filter udara racing 1 mulai berputar pada putaran $5500 \mathrm{rpm}$ dan putaran 6500 rpm-7500 rpm fan (kipas) berputar dengan cepat yang disebabkan dari kevakuman yang besar pada saat putaran rpm tinggi sehingga suplai udara yang masuk ke throttle untuk campuran bahan bakar bertambah untuk menghasilkan campuran bahan bakar yang seimbang serta meningkatkan homogenitas campuran bahan bakar untuk proses pembakaran. Untuk mendapatkan pembakaran yang sempurna, dibutuhkan udara bersih yang banyak mengandung kadar oksigen untuk campuran bahan bakar yang ideal dan berpengaruh pada kinerja mesin yang dihasilkan dari pembakaran (Kambrany, et al., 2014), dengan suplai udara yang bersih untuk campuran bahan bakar yang seimbang dan homogen menghasilkan pembakaran yang lebih sempurna, sehingga daya dan torsi yang dihasilkan meningkat (Fuhaid, 2010: 44).

Berdasarkan hasil dari pengujian CO dan HC emisi gas buang data yang diperoleh dari penggunaan filter udara standar dan filter udara racing ditampikan dalam bentuk tabel dan gambar Grafik 4. Diatas menunjukkan adanya perbedaaan rata-rata emisi gas buang yang dihasilkan dari tiap filter udara yang digunakan.

Dilihat dari Grafik 4. Emisi gas buang CO yang dihasilkan dari mesin sepeda motor menggunakan filter udara standar 0,803\%, filter udara racing 1 0,754\%, dan filter udara racing 2 sebesar 1,034\%. Hasil CO terendah terdapat pada filter udara racing 1 sebesar $0,754 \%$ dan terjadi penurunan kadar emisi gas buang CO pada putaran 3500 rpm sebesar 15\%, peningkatan terjadi pada $4500 \mathrm{rpm}$ sebesar 1\% dari rpm sebelumnya dan $9 \%$ lebih rendah dari filter udara standar, 8\% dari filter udara racing 2. CO tertinggi pada filter udara racing 2 sebesar $1,034 \%$ dan terjadi peningkatan CO 67\% pada putaran $4500 \mathrm{rpm}$ dari rpm sebelumnya menjadi $1,288 \%$ dengan peningkatan 36\% dari filter udara standar dan 81\% dari filter udara racing 1 . Dengan aliran udara turbulence dapat meningkatkan campuran bahan bakar dengan udara menjadi homogen sehingga pembakaran di ruang bakar menjadi sempurna dan kadar emisi gas buang CO dan HC menjadi menurun (Sudrajat,et al., 2013:4$5)$. 
HC yang dihasilkan dari emisi gas buang tertinggi pada filter udara racing 1 dengan hasil 142 ppm lebih tinggi dari filter udara standar dan filter udara racing 2, HC tertinggi pada putaran 3500 rpm 203 ppm, terjadi peningkatan $12 \%$ dari rpm sebelumnya dan penurunan sebesar 33\% diputaran 4500 rpm. HC yang dihasilkan filter udara racing 1 meningkat 66\% dari filter udaara standar dan 39\% dari HC yang dihasilkan filter udara racing 2, HC terendah pada filter udara racing 2 sebesar 111 ppm lebih rendah dari filter udara standar 25\% pada putaran 2500 dan 4\% diputaran 2500 rpm, sedangkan HC yang dihasilkan pada 3500 rpm hanya meningkat $0,8 \%$ dari filter udara standar. Dengan kadar oksigen yang banyak pada udara bersih menjadikan pembakaran bahan bakar didalam ruang bakar lebih sempurna sehingga CO dan HC yang dihasilkan dari pembakaran menjadi menurun (Pratama dan Wardono, 2014: 36).

Perbedaan rata-rata $\mathrm{CO}$ dan $\mathrm{HC}$ yang dihasilkan dari filter udara standar dengan filter udara racing 1 sebesar 0,049\% dan 20 ppm , dan filter udara standar dengan filter udara racing 2 sebesar 0,231\% HC yang dihasilkan 11 ppm, perbedaan CO dan HC pada filter udara racing 1 denga racing 2 sebesar 0,28\% dan HC 31 ppm. Kadar CO terendah pada penggunaan filter udara racing 1 sebesar 0,754\% dan kadar HC terendah dengan menggunakan filter racing 2 dengan HC yang dihasilkan 111 ppm.

\section{SIMPULAN}

Berdasarkan hasil penelitian yang telah dilakukan maka dapat disimpulkan sebagai berikut: 1) Pada penggunaan filter udara racing diperoleh peningkatan performa yang dibandingkan dengan menggunakan filter udara standar. Hal ini terbukti adanya peningkatan performa yang dilihat dari grafik, tabel, dan hasil rata-rata, daya yang dihasilkan menggunakan filter udara racing sebesar 7,35 Hp dengan meningkat Sebesar 2,3\% dibandingkan hasil filter udara standar sebesar
7,18 Hp dan torsi filter udara racing meningkat sebesar $1,6 \%$ menjadi 10,588 N.m dibandingkan menggunakan filter standar sebesar 10,42 N.m. Dengan selisih perbedaan 0,17 Hp dan 0,168 N.m dari performa filter udara standar dan 2) Emisi gas buang CO yang dihasilkan dari penggunaan filter udara racing terdapat peningkatan sebesar $28 \%$ menjadi $1,034 \%$ dan penurunan sebesar $6 \%$ menjadi 0,754\% dibandingkan menggunakan filter udara standar sebesar 0,803\%, dengan selisih perbedaan sebesar $0,231 \%$ dan $0,049 \%$ dari filter udara standar. Pada emisi gas buang HC meningkat sebesar $16 \%$ dan penurunan sebesar 9\% menjadi 142 ppm dan 111 ppm dibandingkan HC yang dihasilkan filter udara standar sebesar 122 ppm, dengan selisih perbedaan sebesar $20 \mathrm{ppm}$ dan $11 \mathrm{ppm}$ dari HC yang dihasilkan filter udara standar. Hal ini terbukti adanya peningkatan dan penurunan kadar emisi gas buang yang dilihat dari grafik, tabel, dan rata-rata data hasil pengujian.

\section{DAFTAR RUJUKAN}

Fuhaid, N. 2010. Pengaruh Filter Udara Pada Karburator Tehadap Unjuk Kerja Mesin Sepeda Motor. Jurnal Teknik Mesin. Diakses 21-7-2016.

Kambrany, M., Farid, A., dan Finahari, N. 2014. Pengaruh Filter Udara Terhadap Unjuk Kerja Mesin Pada Motor Matic. Jurnal Teknik Mesin, PROTON, Vol. 6 /Hal 42-47. Diakses 22-7-2016.

Pratama, D.E. dan Wardono, H. 2014. Pengaruh Variasi Jenis Air dan Kondisi Aktivasi dari Adsorben Arang Sekam Terhadap Prestasi Mesin dan Kandungan Emisi Gas Buang Sepeda Motor Karburator 4Langkah. Jurnal FEMA, VOL. 2, No.1. Diakses 27-11-2016.

Sudrajat, S.C., Ranto, dan Sudibyo, C. 2013. Pengaruh Penggunaan Turbo Elektrik dan Saringan Udara Modifikasi Terhadap Kadar Emisi Gas Buang CO dan HC sepeda motor Honda Supra X 125 Tahun 2009. Jurnal FKIP UNS. Diakses 21-072016. 
137 Jurnal Dinamika Vokasional Teknik Mesin, Volume 3, Nomor 2, Oktober 2018

Sugiyono. 2014. Metode Penelitian Kuantitatif Kualitatif dan $R \& D$. Bandung : ALFABETA.
Suryamin. 2014. Subdirektorat Statistik Transportation. Jakarta : BADAN PUSAT STATISTIK. Diakses 29-42016. 